\title{
Assessment of physico-chemical traits related to eating quality of young dairy bull beef at different ageing times using Raman spectroscopy and chemometrics
}

\author{
Yingqun Nian $^{\mathrm{a}, \mathrm{b}}$, Ming Zhao ${ }^{\mathrm{c}, *}$, Colm P. O'Donnell ${ }^{\mathrm{c}}$, Gerard Downey ${ }^{\mathrm{c}}$, Joseph P. Kerry ${ }^{\mathrm{b}}$, \\ Paul Allen ${ }^{\mathrm{a}}$ \\ a Department of Food Quality and Sensory Science, Teagasc Food Research Centre, Ashtown, Dublin 15, Ireland \\ b School of Food and Nutritional Sciences, University College Cork, Cork, Ireland \\ ${ }^{\mathrm{c}}$ School of Biosystems and Food Engineering, University College Dublin, Belfield, Dublin 4, Ireland
}

A R T I C L E I N F O

\section{Keywords:}

Beef

Chemometrics

Eating quality

Physico-chemical traits

Post-mortem ageing

Raman spectroscopy

\begin{abstract}
A B S T R A C T
Raman spectroscopy and chemometrics were investigated for the prediction of eating quality related physicochemical traits of Holstein-Friesian bull beef. Raman spectra were collected on the 3rd, 7th and 14th days postmortem. A frequency range of $1300-2800 \mathrm{~cm}^{-1}$ was used for partial least squares (PLS) modelling. PLS regression (PLSR) models for the prediction of WBSF and cook loss achieved an $\mathrm{R}^{2} \mathrm{CV}$ of 0.75 with RMSECV of 6.82 $\mathrm{N}$ and an $\mathrm{R}^{2} \mathrm{CV}$ of 0.77 with RMSECV of $0.97 \% \mathrm{w} / \mathrm{w}$ respectively. For the prediction of intramuscular fat, moisture and crude protein content, $\mathrm{R}^{2} \mathrm{CV}$ values were $0.85,0.91$ and 0.70 with $\mathrm{RMSECV}$ of $0.52 \% \mathrm{w} / \mathrm{w}, 0.39 \%$ $\mathrm{w} / \mathrm{w}$ and $0.38 \% \mathrm{w} / \mathrm{w}$ respectively. An $\mathrm{R}^{2} \mathrm{CV}$ of 0.79 was achieved for the prediction of both total collagen and hydroxyproline content, while for collagen solubility the $\mathrm{R}^{2} \mathrm{CV}$ was 0.88 . All samples (100\%) from 15- and 19month old bulls were correctly classified using PLS discriminant analysis (PLS-DA), while 86.7\% of samples from different muscles (longissimus thoracis, semitendinosus and gluteus medius) were correctly classified. In general, PLSR models using Raman spectra on the 3rd day post-mortem had better prediction performance than those on the 7th and 14th days. Raman spectroscopy and chemometrics have potential to assess several beef physical and chemical quality traits.
\end{abstract}

\section{Introduction}

Meat quality is a complex concept that involves intrinsic cues (i.e. safety, shelf-life, nutritional value, eating quality) and extrinsic cues (i.e. brand, quality label, origin, convenience of the product). Of these, eating quality is a critical parameter to determine consumer preferences, including sensory quality (i.e. tenderness, juiciness and flavour) and physico-chemical traits: technological quality (i.e. WarnerBratzler shear force (WBSF) and cook loss; compositional quality (i.e. intramuscular fat (IMF), collagen and moisture content) (Prieto et al., 2009; Troy \& Kerry, 2010).

The amount and solubility of intramuscular connective tissue (IMCT) and post-mortem proteolysis of myofibrillar proteins influence beef tenderness predominately. Collagen, as a major component of IMCT, is believed to contribute to the "background" toughness of beef after prolonged ageing. It has been generally accepted that higher levels of total collagen and particularly lower collagen solubility are associated with reduced beef tenderness (Jeremiah et al., 2003a). IMF produces marbling effects in beef, which is positively linked to beef tenderness, juiciness and flavour (Scollan et al., 2006). A higher level of moisture in beef can lead to higher cook loss and lower tenderness (Chambaz et al., 2003). An increased cook loss has a negative effect on beef tenderness (Silva et al., 1999).

Ageing is the most influential primary processing factor involving complex changes in muscle metabolism in the post slaughter period. Post-mortem proteolysis is a pronounced action during ageing, which greatly contributes to meat tenderization (Muchenje et al., 2009). Moreover, water mobility and biomechanical changes of IMCT in meat during ageing are also associated with changes in quality parameters, including juiciness and tenderness (Pearce et al., 2011; Nishimura, 2015).

Previous studies have demonstrated the potential of Raman spectroscopy (RS) combined with chemometric approaches to measure WBSF and cook loss of aged meat. A regression coefficient determination of cross validation $\left(\mathrm{R}^{2} \mathrm{CV}\right)$ of 0.75 for the prediction of shear force (SF) in roasted beef silversides was reported by Beattie et al. (2004)

\footnotetext{
* Corresponding author.

E-mail address: ming.zhao@ucd.ie (M. Zhao).
} 
while $\mathrm{R}^{2} \mathrm{CV}$ s of $0.33-0.79$ were obtained for the prediction of intact fresh bovine gluteus medius (GM) muscles SF at the 14th day postmortem using a portable Raman system (Bauer et al., 2016). $\mathrm{R}^{2} \mathrm{CVs}$ of $0.79-0.86$ for SF and $0.79-0.83$ for cook loss were obtained for intact frozen/thawed sheep meat after ageing for 5 days using a prototype handheld Raman system (Schmidt et al., 2013). In contrast, a very low $\mathrm{R}^{2} \mathrm{CV}$ of 0.06 was obtained using a handheld Raman device for SF prediction on intact fresh lamb muscle at the 1st day post-mortem by Fowler et al. (2014). However, none of these studies have reported on homogenized meat samples, and previous studies only focused on one type of muscle and one specific ageing time; the prediction ability for different muscle types and different ageing times has not been investigated to date.

A rapid and applicable method for compositional quality assessment would be highly appreciated by the meat industry. Near infrared spectroscopy (NIRS) has been employed to predict chemical composition of beef with $\mathrm{R}^{2} \mathrm{CVs}$ of $0.16-0.82$ for predictions of crude protein (Alomar et al., 2003; Ripoll et al., 2008), $\mathrm{R}^{2} \mathrm{CVs}$ of 0.76-0.99 for IMF (Rødbotten et al., 2000; De Marchi et al., 2007), $\mathrm{R}^{2} \mathrm{CVs}$ of 0.09-0.91 for moisture (Cozzolino et al., 2002; De Marchi et al., 2007) and $\mathrm{R}^{2} \mathrm{CVs}$ of 0.18-0.44 were reported for collagen prediction (Alomar et al., 2003; De Marchi et al., 2007). Hyperspectral imaging has been reported to be effective for the prediction of hydroxyproline content in chicken meat $\left(R^{2} C V\right.$ - 0.87) (Xiong et al., 2015). Compared with NIRS, RS has been claimed to provide more detailed information on chemical structures and physical forms for the identification of substances by their characteristic spectral patterns - 'fingerprinting' and for quantitative detection of the amount of a substance in a sample (Smith \& Dent, 2005). However, recent studies using RS on lamb were unable to predict collagen and for IMF obtained an $\mathrm{R}^{2} \mathrm{CV}$ of 0.02 (Fowler et al., 2015). The authors of this study are not aware of any previous research investigating the use of RS to determine chemical composition of beef particularly for collagen characteristics. Moreover, the previous studies were mainly focused on sole physical or chemical trait of meat, while the prediction performance of RS on a wide range of beef physical and chemical traits has not been explored.

Beef quality can also be largely affected by on-farm production factors, such as animal breed, slaughter age, sex, feeding regime, muscle location etc. (Frylinck et al., 2013). The clear discrimination of beef according to production factors could not just solely be used to identify meat origin, but also as a marker to select meat cuts based on expected quality properties. In addition to the conventional analytical methods for muscle identification such as DNA, immunological and chromatographic techniques, RS has been shown to be a potential tool for rapid assessment of food adulteration and discrimination between species and muscle groups within species (Herrero, 2008; Damez \& Clerjon, 2008).

The objectives of this study are to use RS and chemometrics to (1) develop models for the prediction of key physico-chemical traits of young bull beef; (2) select the most representative wavelengths for these predictions; (3) compare prediction performance during beef ageing; (4) discriminate beef samples from three muscle types or from two slaughter ages.

\section{Materials and methods}

\subsection{Source of materials}

For the prediction models, Holstein-Friesian (HF) bulls $(\mathrm{n}=49)$ were slaughtered in a commercial abattoir. The longissimus thoracis (LT) muscle samples were removed from the carcasses of 35 bulls at $48 \mathrm{~h}$ post-mortem at $4{ }^{\circ} \mathrm{C}$. LT and semitendinosus (ST) muscles were removed from the carcasses of the remaining 14 bulls. At $72 \mathrm{~h}$ post-mortem, muscle samples $(n=63)$ were cut into individual slices $(\sim 25 \mathrm{~mm}$ thick) and vacuum-packed using five-layer (PA/tie/PE/tie/PE) coextruded nanocomposite films (Versatile Packaging Ltd., Ireland) and a
VG 400 ILPRA sealing machine (Vigevano, Italy). Samples for chemical analysis and Raman spectra measurement on the 3rd day post-mortem were immediately stored at $-20^{\circ} \mathrm{C}$; while samples for Raman spectra measurements at the 7 th and 14 th days post-mortem were aged for 7 and 14 days at $4{ }^{\circ} \mathrm{C}$ respectively and then stored at $-20^{\circ} \mathrm{C}$.

For the discrimination models, 30 bulls were slaughtered at 15months $(n=15)$ and 19-months $(n=15)$ of age respectively. LT, ST and GM muscles were collected from 10 bulls (15-months of age), and were used for muscle type discrimination. For age discrimination, 26 muscles (LT \& ST) were collected from 15-month old bulls, and 29 muscles (LT \& ST) were collected from 19-month old bulls. Two individual slices were cut from each muscle and vacuum-packed after ageing for 7 and 14 days at $4{ }^{\circ} \mathrm{C}$ respectively, and then frozen at $-20{ }^{\circ} \mathrm{C}$ prior to Raman spectra measurements.

\subsection{Warner-Bratzler shear force and cook loss}

Trimmed beef steaks which had been aged for 3 days (150-180 g) were thawed in constantly circulating water at 10 to $15^{\circ} \mathrm{C}$. The steaks were then cooked in open bags suspended in a water bath (TC120, Grant Instruments Ltd., England) at $72{ }^{\circ} \mathrm{C}$ until the temperature in the centre of the steak reached $70^{\circ} \mathrm{C}$. Cook loss was determined as:

$($ (raw weight - cooked weight $) /$ raw weight $) \times 100 \%$.

Steaks were immediately cooled and held overnight at $4{ }^{\circ} \mathrm{C}$. Seven meat cores ( $12.5 \mathrm{~mm}$ diameter) were cut parallel to the longitudinal orientation of the muscle fibres for each sample. When the cores reached room temperature, they were sheared using the WarnerBratzler (WB) shear blade attached to an Instron Universal Testing Machine (Models 5543, Instron (UK) Ltd., High Wycombe, UK). A $500 \mathrm{~N}$ load cell was used with a crosshead speed $50 \mathrm{~mm} / \mathrm{min}$. The average maximum shear force was calculated by excluding the two extreme values from seven acquisitions.

\subsection{IMF, moisture and protein}

Frozen samples which had been aged for 3 days were thawed at $4{ }^{\circ} \mathrm{C}$ for $\sim 16 \mathrm{~h}$. After all external fat was trimmed the lean beef and exudate were homogenized together using a blender (R301 Ultra, Robot Coupe SA, France). Moisture and IMF concentrations were measured using a smart microwave moisture drying oven and an NMR Smart Trac rapid Fat Analyser (CEM Corporation, USA) using AOAC official method 985.14 (AOAC, 1991). Protein concentration was determined using a LECO FP328 (LECO Corp., MI, USA) protein analyser based on the Dumas method according to AOAC method 992.15 (AOAC, 1992). All composition tests were carried out as two determinations per sample with a standard deviation between replicates below $1.00 \%$.

\subsection{Collagen content and solubility}

Samples which had been aged for 3 days were freeze dried and then milled to a fine homogenate. Approximately $4 \mathrm{~g}$ of muscle homogenate was defatted using $20 \mathrm{~mL}$ of diethyl ether overnight and re-dried. The heat-soluble collagen was extracted as described by Hill (1966) with slight modifications. Briefly, $2.5 \mathrm{~g}$ of fat-free dry (FFD) muscle hydrolysate was heated in water bath for $2 \mathrm{~h}$ at $90{ }^{\circ} \mathrm{C}$ with $15 \mathrm{~mL}$ of Ringer's solution. Sample solution was centrifuged (LYNX 6000, Thermo Scientific) twice at $3990 \mathrm{~g}$ for $10 \mathrm{~min}$ at room temperature. The supernatants from the two centrifugations were combined. Then $100 \mu \mathrm{L}$ of final supernatant and $3 \mathrm{mg}$ of FFD (total collagen) of each muscle (in triplicate) were hydrolysed using $2 \mathrm{~mL}$ of $6 \mathrm{M} \mathrm{HCl}$ under nitrogen in sealed vials at $110{ }^{\circ} \mathrm{C}$ overnight. Following hydrolysis, the vials were cooled and centrifuged (5174C/R, Eppendorf, UK) at 18,187g for $1 \mathrm{~min}$ at room temperature to remove particulate matter.

Quantitative analysis of hydroxyproline in FFD muscle hydrolysates was carried out using LC-MS/MS with slight modifications of the method reported by Colgrave et al. (2008). Briefly, $100 \mu \mathrm{L}$ aliquots of 
the hydrolysates were dried under nitrogen and reconstituted in $1 \mathrm{~mL}$ of $0.1 \%$ formic acid. $100 \mu \mathrm{L}$ of $0.1 \%$ formic acid was added to $100 \mu \mathrm{L}$ of the reconstituted sample and then $5 \mu \mathrm{L}$ of the final reconstituted sample was injected into a Waters Acquity UPLC system with an ACQUITY UPLC@BEH C18 $(50 \mathrm{~mm} \times 2.1 \mathrm{~mm}$, particle size $1.7 \mu \mathrm{m})$ column coupled to tandem mass spectrometry (Waters Corp, MA, USA). The flow rate was $0.5 \mathrm{~mL} / \mathrm{min}$ using an isocratic flow of $95 \%$ solvent A ( $0.1 \%$ formic acid in HPLC water) and $5 \%$ solvent B $(0.1 \%$ formic acid in Acetonitrile). Data acquisition and processing were performed using the Target Lynx Software (Waters Corp, MA, USA).

Rat tail ( $\alpha-1$ (1) chain) (Enzo Life Sciences, Farmingdale, NY, EEUU) was used as the quality control collagen standard for validation. An aliquot of $100 \mu \mathrm{L}$ of rat tail solution was hydrolysed and reconstituted using the same procedure with samples, then diluted with $0.1 \%$ formic acid in order to obtain three different standards in the high, medium and low levels of hydroxyproline. The concentration of hydroxyproline (nmol/L) was determined from integration of the area under the curve against a standard curve with a linear range from 100 to $5000 \mathrm{nmol} / \mathrm{L}$ $\left(r^{2}=0.99\right)$. The conversion of this data to mass of collagen was as previously described (Colgrave et al., 2008). Percentage solubility was calculated as soluble hydroxyproline divided by total hydroxyproline multiplied by 100 . All collagen properties were determined in triplicate for each sample and averaged.

\subsection{Sample preparation and Raman measurements}

Raman spectroscopic data were collected from scanning aged beef samples on the 3rd, 7th and 14th days post-mortem. Before measurements, frozen steaks were removed from $-20{ }^{\circ} \mathrm{C}$ storage and allowed to thaw at $4{ }^{\circ} \mathrm{C}$ for $\sim 16 \mathrm{~h}$. Each sample was homogenized using a Robot Coupe R301 ultra (Vincennes, France) for $1 \mathrm{~min}$. Approximately $10 \mathrm{~g}$ of homogenized beef sample was wrapped in PVC clingfilm to form a ball. Raman spectra were collected on a DXR SmartRaman spectrometer (ThermoFisher Scientific UK Ltd., Loughborough, UK) equipped with a diode laser operating at $780 \mathrm{~nm}$ to minimize sample fluorescence issues and a charge coupled device (CCD) detector operating at $-50{ }^{\circ} \mathrm{C}$. A smooth side of the wrapped sample was then placed over the aperture ( $50 \mu \mathrm{m}$ slit) of the universal platform sampling (UPS) accessory. All spectra of each sample were accumulated for 5 min (i.e. $15 \mathrm{~s}$ exposure time $\times 20$ exposures) using a $150 \mathrm{~mW}$ laser power. Samples were scanned in random order at ambient temperature $\left(\sim 20^{\circ} \mathrm{C}\right)$. Raman intensity counts per second (cps) were recorded over the wavelength range $250-3380 \mathrm{~cm}^{-1}$ at $2 \mathrm{~cm}^{-1}$ intervals. Cosmic spikes were removed automatically by the supplied software. Instrument control, spectral acquisition, and file conversion were performed using the supplied OMNIC software v 9.2.98 (Thermo Fisher Scientific Inc., USA). Each sample was scanned twice, once each at two different scan sites on the sample ball; the mean of these replicate spectra was used in subsequent chemometric operations.

\subsection{Spectral data processing}

Raw Raman spectra were exported from OMNIC software as JCAMP.DX files and imported into Matlab 2014a (The Mathworks, Natick, MA, USA), the mean spectrum of each sample was calculated and also imported into The Unscrambler v.10.3 (Camo, Trondheim, Norway) for different data-pretreatments and chemometric operations.

Baseline correction of Raman data was carried out using the Savitzky-Golay (S.G.) derivation. First derivatives were calculated using a fifth-degree polynomial and 7 smoothing points; second derivatives were calculated using a fifth-degree polynomial and 9 smoothing points. Multiplicative effects of the spectroscopic data were removed using unit vector normalisation. In order to find the optimal data preprocessing method for partial least squares model development, other baseline correction methods such as polyfit using a fifth-degree polynomial were also employed.

\subsection{Chemometric analysis}

For the prediction of beef quality traits, partial least squares regression (PLSR) models were developed using pre-processed Raman spectroscopic data collected on the 3rd, 7th or 14th days post-mortem using selected frequency ranges (i.e. $250-3380 \mathrm{~cm}^{-1}, 900-1800 \mathrm{~cm}^{-1}$, $1300-2800 \mathrm{~cm}^{-1}$ ) respectively combined with the reference values of the physico-chemical traits measured on the 3rd day. Full cross-validation PLSR models were developed using 63 samples to predict WBSF, cook loss, IMF, moisture and protein content and 36 samples for the prediction of total collagen (TC), hydroxyproline (HYP) and collagen solubility (CSol). It was assumed that prediction performance of these PLSR models developed using Raman spectral data collected after a longer post-mortem duration would have lower accuracy as the reference data was obtained from the 3rd post mortem day. Evaluation of PLSR model prediction performance was carried out using the statistics parameters such as root mean square error of calibration (RMSEC) and cross-validation (RMSECV) and the coefficient of determination on calibration $\left(\mathrm{R}^{2} \mathrm{C}\right)$ and cross-validation $\left(\mathrm{R}^{2} \mathrm{CV}\right)$. For a satisfactory prediction performance, the value of $\mathrm{R}^{2}$ is expected to be close to 1 while values of RMSE and bias are expected to be close to 0 .

Partial least squares discriminant analysis (PLS-DA) models were developed using pre-processed Raman spectroscopic data of 55 and 30 beef samples (aged for both 7 and 14 days) in the frequency range of $1300-2800 \mathrm{~cm}^{-1}$ for the classification of slaughter age (15- and 19month old) and muscles (LT, ST and GM), respectively. For the PLS-DA models developed for the detection of bull age, dummy y values of 1 and 2 were assigned to samples ( 1 for beef from 15-month old bulls, 2 for beef from 19-month old bulls); the threshold selected for classification was set empirically at 1.5. Likewise, for muscle determination, the dummy y values of 1,2 and 3 were given to samples of LT, ST and GM muscles respectively with the empirical thresholds of 1.5 for the classification of LT and ST and 2.5 for the classification of ST and GM. To evaluate the performance of PLS-DA models, confusion matrices were developed for the classification of slaughter age and muscle based on the explanatory matrices (Table $1 \mathrm{a} \& \mathrm{~b}$ ). The correct classification (CC) used to evaluate PLS-DA models was expressed as percentage:

$\mathrm{CC}=\frac{\mathrm{TP}+\mathrm{TN}}{\mathrm{TP}+\mathrm{FP}+\mathrm{FN}+\mathrm{TN}}$

In the current study, all PLS models were calibrated using the nonlinear iterative partial least squares (NIPALS) algorithm. Improvements in performance of PLS models were attempted using a reduced number of Raman spectral variables. The Martens' uncertainty test was applied to select spectral variables based on the variability of their regression coefficients during cross-validation of model development (Martens \& Martens, 2000). Other informative variable selection algorithms such as variable importance on projection (VIP) (Chong \& Jun, 2005) and significance multivariate correlation (sMC) (Tran et al., 2014) were also explored.

\section{Results and discussion}

\subsection{Meat quality results}

WBSF of samples ranged from 25.1-86.6 N (Table 2), with 4 samples below $31.36 \mathrm{~N}$, which was categorized into a 'very tender' group; 4 and 9 samples ranged from $31.36-38.22 \mathrm{~N}$ and $38.22-45.08 \mathrm{~N}$, belonging to 'tender' and 'intermediate tender' categories, respectively. The WBSF of the other 46 samples was above $45.08 \mathrm{~N}$, considered as a 'tough' group (Shackelford et al., 1991). In the current study, cook loss ranged between $26.6 \% \mathrm{w} / \mathrm{w}$ and $36.7 \% \mathrm{w} / \mathrm{w}$, which was in accordance with previous work (Jeremiah et al., 2003b).

IMF content in the current study ranged from $0.05-5.81 \% \mathrm{w} / \mathrm{w}$, and most samples were within the range of $0.76 \%-6.00 \% \mathrm{w} / \mathrm{w}$ reported for beef in previous studies (Jeremiah et al., 2003b; Muchenje et al., 2008). 
Table 1

Confusion matrix for the classification of samples.

a. At the age of 15-month (defining as and 19-month defining as true or false - positive and true or false - negative).

\begin{tabular}{llll}
\hline & & Measured bull age \\
\cline { 3 - 4 } & & 15-Month & 19-Month \\
\hline Predicted bull age & 15-Month & True positive (TP) & False positive (FP) \\
19-Month & & False negative (FN) &
\end{tabular}

b. From beef cuts of LT, ST and GM muscles (defining as true or false - positive and true or false negative).

\begin{tabular}{|c|c|c|c|c|c|}
\hline & & & \multicolumn{2}{|l|}{ Measured muscle type } & \multirow[b]{2}{*}{ GM } \\
\hline & & & $\mathrm{LT}$ & ST & \\
\hline \multirow[t]{3}{*}{ PLS-DA modelling for LT determination } & \multirow[t]{3}{*}{ Predicted muscle type } & LT & True positive (TP) & False negative (FN) & False negative (FN) \\
\hline & & ST & False positive (FP) & True negative (TN) & True negative (TN) \\
\hline & & GM & False positive (FP) & True negative (TN) & True negative (TN) \\
\hline \multirow[t]{3}{*}{ PLS-DA modelling for ST determination } & \multirow[t]{3}{*}{ Predicted muscle type } & LT & False negative (FN) & False positive (FP) & False negative (FN) \\
\hline & & ST & True negative (TN) & True positive (TP) & True negative (TN) \\
\hline & & GM & True negative (TN) & False positive (FP) & True negative (TN) \\
\hline \multirow[t]{3}{*}{ PLS-DA modelling for GM determination } & \multirow[t]{3}{*}{ Predicted muscle type } & LT & True negative (TN) & True negative (TN) & False positive (FP) \\
\hline & & ST & True negative (TN) & True negative (TN) & False positive (FP) \\
\hline & & GM & False negative (FN) & False negative (FN) & True positive (TP) \\
\hline
\end{tabular}

Table 2

Reference values of meat quality traits of young dairy bull beef on the 3rd day postmortem.

\begin{tabular}{lccccc}
\hline & $\mathrm{n}$ & Mean & Min & Max & SD \\
\hline Physical traits & & & & & \\
WBSF (N) & 63 & 53.0 & 25.1 & 86.6 & 13.4 \\
Cook loss (\%w/w) & 63 & 32.7 & 26.7 & 36.7 & 2.03 \\
Chemical traits & & & & & \\
IMF (\%w/w) & 63 & 1.69 & 0.05 & 5.81 & 1.31 \\
Protein (\%w/w) & 63 & 22.7 & 21.2 & 24.3 & 0.69 \\
Moisture (\%w/w) & 63 & 74.7 & 71.6 & 77.5 & 1.27 \\
Total collagen (mg/g) & 36 & 3.27 & 1.51 & 6.02 & 1.19 \\
Total hydroxyproline (mg/g) & 36 & 0.44 & 0.20 & 0.81 & 0.16 \\
Collagen solubility (\%) & 36 & 18.0 & 6.95 & 30.6 & 5.73 \\
\hline
\end{tabular}

WBSF, Warner-Bratzler shear force; IMF, intramuscular fat; n, numbers of samples; SD, standard deviation.

Generally, 3-7\%w/w of IMF is considered as an ideal range to ensure palatability while not being detrimental to human health (Miller, 2002). Moisture, the most abundant component in beef, varied from $71.6-77.5 \% \mathrm{w} / \mathrm{w}$ with a standard deviation of $1.27 \% \mathrm{w} / \mathrm{w}$. Total protein content varied from 21.2 to $24.3 \% \mathrm{w} / \mathrm{w}$ with a low standard deviation of $0.69 \% \mathrm{w} / \mathrm{w}$ and a mean value of $22.7 \% \mathrm{w} / \mathrm{w}$, which is in agreement with the reported range for beef chemical composition values (Muchenje et al., 2009). The mean value of total collagen $(3.27 \mathrm{mg} / \mathrm{g}$ ) or collagen solubility $(18.0 \%)$ was in agreement with studies by other authors (Archile-Contreras et al., 2010; Christensen et al., 2011). The wide range of collagen values used in this study was due to the different muscles selected as inter muscle comparisons is considered as an important reason for samples obtaining large variation in collagen content, which consequently leads to the strong relationship between collagen characteristics and cooked meat tenderness (Dransfield, 1977).

\subsection{Raman spectra}

Raw Raman spectra $\left(250-3380 \mathrm{~cm}^{-1}\right)$ of all bull beef samples ( $n=189$, the sum of samples of all ageing times) including the background fluorescence are shown in Fig. 1a. All sample spectra have very similar spectral profiles. Averaged spectra derived from the raw spectra $(n=63)$ of each ageing time are shown in Fig. 1b. The spectra of the 3rd and 7th days almost overlap each other, while the spectrum of the 14th day is separated from them in the frequency range of $250-2800 \mathrm{~cm}^{-1}$. In Fig. 1c, fluorescence effects and multiplicative effects have been removed; detailed Raman signals are shown for the mean spectrum of all bull beef samples in the frequency range of $500-2800 \mathrm{~cm}^{-1}$. The Raman spectral signal around $670 \mathrm{~cm}^{-1}$ is related to methionine and disulphide $\mathrm{S}-\mathrm{S}$ stretching vibration (Beattie et al., 2004). Signals of myoglobin in meat are shown at 714, 755, 855, 1125, 1340 and $1540 \mathrm{~cm}^{-1}$; signals of tyrosine (aromatic amino acid side chains) are shown at 825 and $855 \mathrm{~cm}^{-1}$ (Bauer et al., 2016). The spectral regions of $890-1060$ and $1645-1685 \mathrm{~cm}^{-1}$ assigned to the amide I bands involve $\mathrm{C}-\mathrm{C}$ stretching vibrations, $\mathrm{C}=\mathrm{O}$ stretching and $\mathrm{N}-\mathrm{H}$ in-plane bending of peptide bonds; the region of $1200-1350 \mathrm{~cm}^{-1}$ assigned to amide III bands mainly involve $\mathrm{C}-\mathrm{N}$ stretching and $\mathrm{N}-\mathrm{H}$ in-plane bending vibrations of the peptide groups (Herrero et al., 2008). Peaks at 1270 and $1336 \mathrm{~cm}^{-1}$ have been related to the secondary and tertiary structures of proteins, i.e., amide III bands. A peak at $1650 \mathrm{~cm}^{-1}$ is probably due to $\alpha$-helical structures, while those at 1270 and $1300 \mathrm{~cm}^{-1}$ have been attributed to $\alpha$ globularand $\alpha$ fibrous-helix formations of amide III (Beattie et al., 2004). Phenylalanine is a strong scatter at $1003 \mathrm{~cm}^{-1}$, tryptophan shows specific peaks at 1353 and $1550 \mathrm{~cm}^{-1}$, which are another two typical signals attributed to the aromatic amino acid side chains. Peaks at $1439-1447 \mathrm{~cm}^{-1}$ have been attributed to a $\mathrm{CH}_{2}$ scissoring vibration in proteins (Beattie et al., 2004). Raman spectral peaks at frequencies of $1744,1653,1439,1300,1270,1125$, and $920 \mathrm{~cm}^{-1}$ have also been assigned to the $\mathrm{C}=\mathrm{O}, \mathrm{C}=\mathrm{C}$ stretching bonds, $\mathrm{CH}_{2}$ scissoring or twisting bonds, and $\mathrm{C}-\mathrm{H}$ in-plane deformation bonds of aliphatic chains in lipids (Li-Chan, 1996). The peak shown at $2327 \mathrm{~cm}^{-1}$ is most likely related to $\mathrm{C} \equiv \mathrm{N}$ stretching bonds of aliphatic nitriles (Socrates, 2001).

\subsection{Prediction of physico-chemical traits based on PLS regression models}

Performance of PLS models developed on pre-treated Raman data using Savitzky Golay (S.G.) derivation or polyfit with 5th baseline correction methods were examined; models developed in selected ranges (i.e. $250-3380 \mathrm{~cm}^{-1}, 900-1800 \mathrm{~cm}^{-1}$ and $1300-2800 \mathrm{~cm}^{-1}$ ) were also explored. Results showed that PLS models developed using S.G. derivation pre-treated Raman spectra over $1300-2800 \mathrm{~cm}^{-1}$ 
a)

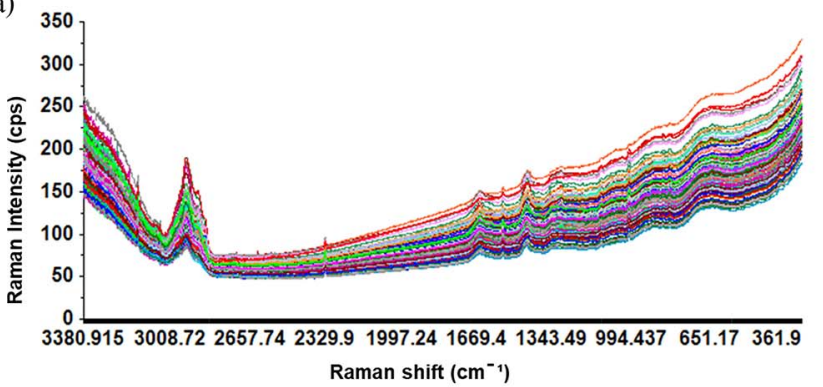

b)

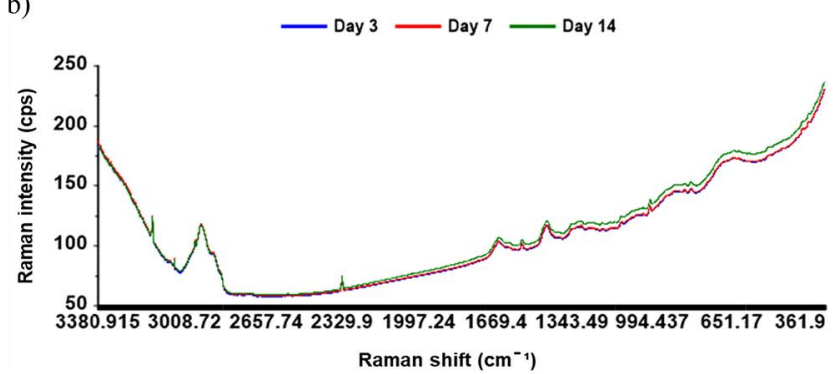

c)

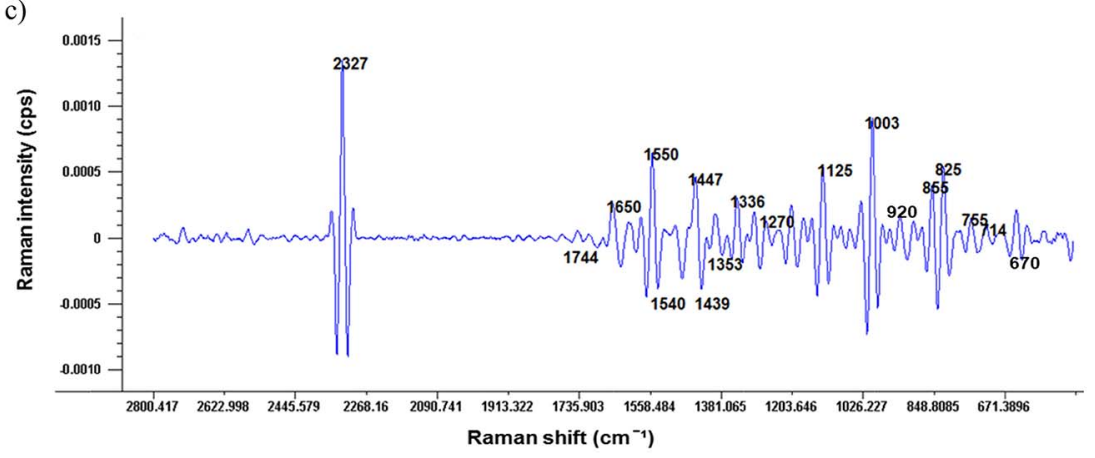

Fig. 1. a) Raw Raman spectra $\left(250-3380 \mathrm{~cm}^{-1}\right)$ of all bull beef samples ( $\mathrm{n}=189) ; \quad$ b) averaged raw Raman spectra $\left(250-3380 \mathrm{~cm}^{-1}\right)$ of bull beef samples $(\mathrm{n}=63)$ from the 3rd, 7th and 14th day post-mortem, respectively; c) Averaged Raman spectra $\left(500-2800 \mathrm{~cm}^{-1}\right)$ of all bull beef samples $(\mathrm{n}=189)$ pre-treated by the Savitzky Golay second derivative using a fifth-degree of polynomial and 7 smoothing points and normalisation.

Table 3

Summary of PLSR model performances (Raman shift $1300-2800 \mathrm{~cm}^{-1}$ ) for WBSF and cook loss prediction in bull beef.

\begin{tabular}{|c|c|c|c|c|c|c|c|c|}
\hline & Sample & $\begin{array}{l}\text { Raman data pre-treatment with the Martens' uncertainty } \\
\text { test }\end{array}$ & $\begin{array}{l}\text { Numbers of spectral variables } \\
\text { retained }\end{array}$ & \# PLS loadings & $\mathrm{R}^{2} \mathrm{C}$ & RMSEC & $\mathrm{R}^{2} \mathrm{CV}$ & RMSECV \\
\hline \multirow[t]{6}{*}{ WBSF } & Day $3(n=63)$ & $\begin{array}{l}\text { S.G. 1st der. using } 5 \text { th polynomial with } 7 \text { smooth } \\
\text { points + nor.u.v. }\end{array}$ & 130 & 2 & 0.88 & 4.70 & 0.75 & 6.82 \\
\hline & & S.G. 2 nd der. using 2 th polynomial with 9 smooth points & 60 & 2 & 0.70 & 7.22 & 0.45 & 9.98 \\
\hline & Day $7(n=63)$ & $\begin{array}{l}\text { S.G. 1st der. using } 5 \text { th polynomial with } 7 \text { smooth points } \\
+ \text { nor.u.v. }\end{array}$ & 107 & 2 & 0.84 & 5.12 & 0.70 & 7.22 \\
\hline & & S.G. 2nd der. using 2 th polynomial with 9 smooth points & 87 & 2 & 0.86 & 4.86 & 0.73 & 6.98 \\
\hline & Day $14(\mathrm{n}=63)$ & $\begin{array}{l}\text { S.G. 1st der. using } 5 \text { th polynomial with } 7 \text { smooth points } \\
+ \text { nor.u.v. }\end{array}$ & 56 & 1 & 0.76 & 6.29 & 0.70 & 7.26 \\
\hline & & S.G. 2nd der. using 2 th polynomial with 9 smooth points & 62 & 1 & 0.72 & 6.91 & 0.63 & 7.97 \\
\hline \multirow[t]{6}{*}{ Cook loss } & Day $3(n=63)$ & $\begin{array}{l}\text { S.G. 1st der. using } 5 \text { th polynomial with } 7 \text { smooth } \\
\text { points }+ \text { nor.u.v. }\end{array}$ & 97 & 1 & 0.83 & 0.82 & 0.77 & 0.97 \\
\hline & & S.G. 2nd der. using 2 th polynomial with 9 smooth points & 73 & 2 & 0.71 & 1.08 & 0.54 & 1.39 \\
\hline & Day $7(n=63)$ & $\begin{array}{l}\text { S.G. 1st der. using } 5 \text { th polynomial with } 7 \text { smooth points } \\
+ \text { nor.u.v. }\end{array}$ & 78 & 2 & 0.76 & 0.98 & 0.55 & 1.36 \\
\hline & & S.G. 2nd der. using 2 th polynomial with 9 smooth points & 56 & 2 & 0.61 & 1.24 & 0.45 & 1.51 \\
\hline & Day $14(n=63)$ & $\begin{array}{l}\text { S.G. } 1 \text { st der. using } 5 \text { th polynomial with } 7 \text { smooth points } \\
+ \text { nor.u.v. }\end{array}$ & 60 & 2 & 0.81 & 0.85 & 0.62 & 1.21 \\
\hline & & S.G. 2nd der. using 2 th polynomial with 9 smooth points & 60 & 1 & 0.58 & 1.26 & 0.48 & 1.41 \\
\hline
\end{tabular}

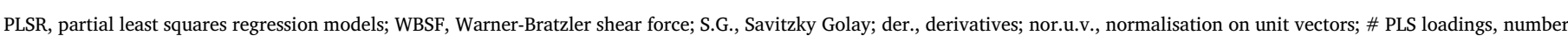

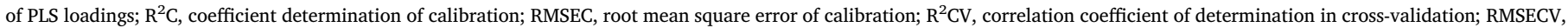
root mean square error of cross-validation; Day 3, the 3rd day post-mortem; Day 7, the 7th day post-mortem; Day 14, the 14th day post-mortem; n, numbers of samples. 

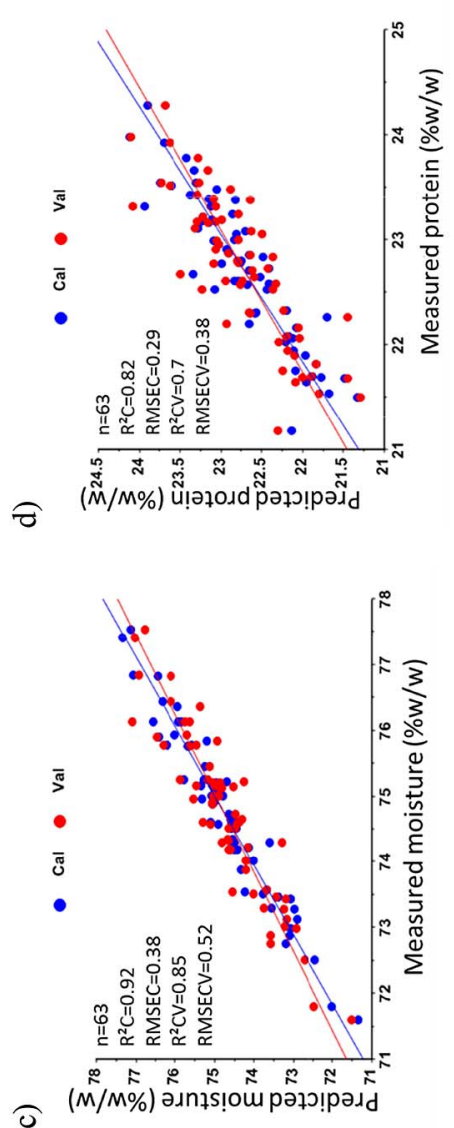

o
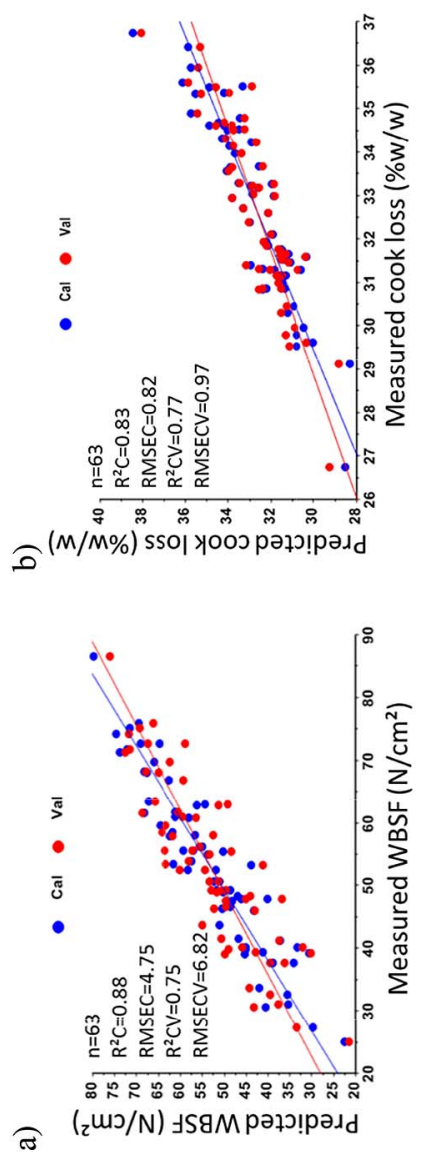

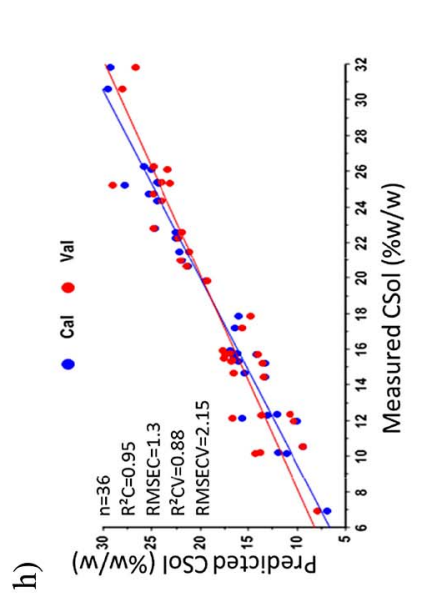

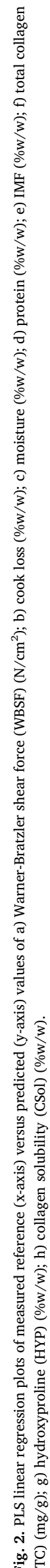




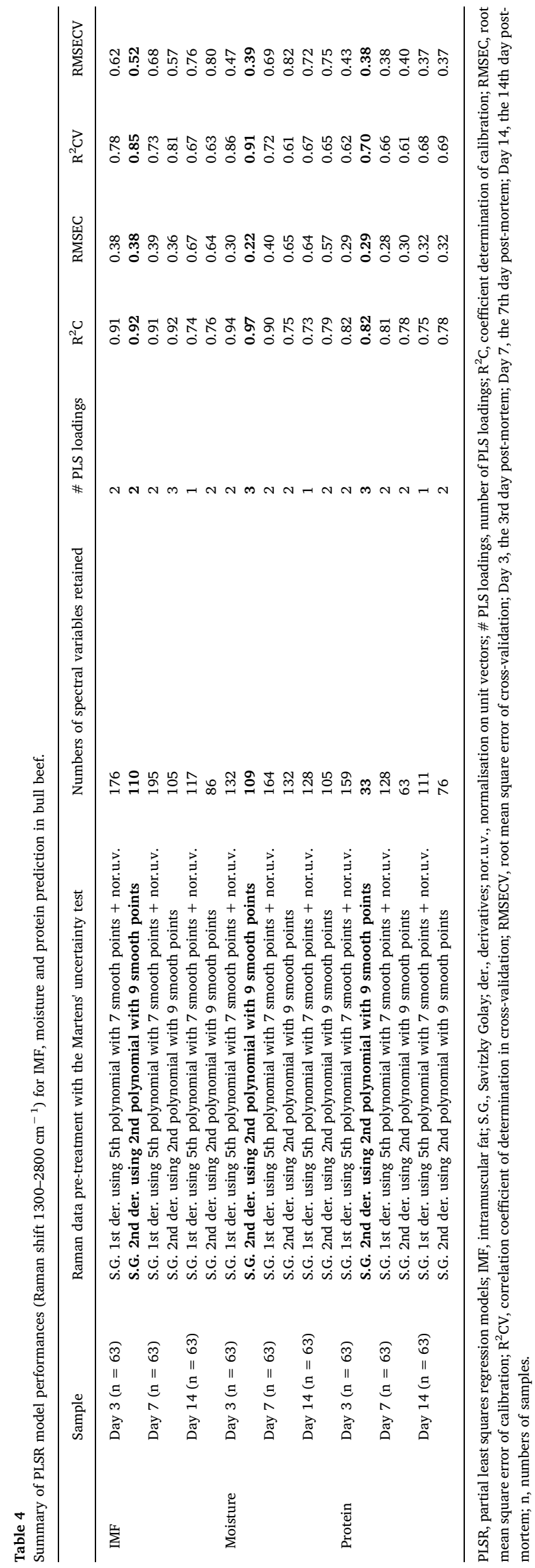

performed best for both prediction and discrimination purposes; especially for the prediction of TC, HYP and CSol. In the current study, the Martens' uncertainty test was demonstrated to be the most effective method to select the informative Raman spectral variables for enhancing the PLS model performance. Therefore, all models were developed using retained Raman spectral variables in the Raman shifts of $1300-2800 \mathrm{~cm}^{-1}$ after the Martens' uncertainty test, and results derived from $900-1800 \mathrm{~cm}^{-1}, 250-3380 \mathrm{~cm}^{-1}$ and from other informative spectral variable selection algorithms (i.e. VIP and sMC) are not discussed in this paper.

\subsubsection{Prediction of WBSF and cook loss}

Summary statistic results of the PLSR models developed for the predictions of WBSF and cook loss are shown in Table 3. Generally, one or two latent variables were required to attain RMSECV values of 6.82-9.98 N for WBSF and $0.97-1.51 \% \mathrm{w} / \mathrm{w}$ for cook loss. The models developed using Raman spectra which were collected on the 3rd day post-mortem had a higher prediction performance than those collected on the 7th and 14th days. For the prediction of WBSF, the best prediction results achieved an $\mathrm{R}^{2} \mathrm{C}$ of $0.88, \mathrm{R}^{2} \mathrm{CV}$ of 0.75 , RMSEC of $4.7 \mathrm{~N}$ and RMSECV of $6.82 \mathrm{~N}$ (Fig. 2a). For the prediction of cook loss, an $\mathrm{R}^{2} \mathrm{C}$ of 0.83 with RMSEC of $0.82 \% \mathrm{w} / \mathrm{w}$ and $\mathrm{R}^{2} \mathrm{CV}$ of 0.77 with RMSECV of $0.97 \% \mathrm{w} / \mathrm{w}$ were obtained (Fig. $2 \mathrm{~b}$ ). The results show the changes in beef tenderness during ageing.

It is well established that ageing can be used to reduce WBSF values during post-mortem storage due to the proteolysis of myofibrillar proteins (Muchenje et al., 2009). Cook loss also changed considerably during ageing. It also has been reported that cook loss generally increases with ageing in beef GM and LL muscles (Colle et al., 2015). Most of the water loss during cooking is from the juice expelled by heatinginduced shrinkage which occurs in the myofibrillar matrix due to protein denaturation (Hughes et al., 2014). During ageing, myofibrillar strain is reduced by proteolysis contributing to an inflow of extramyofibrillar water to the intra-myofibrillar space. The swelling of the intra-myofibrillar space appears to increase water storage before heating (Pearce et al., 2011). Also protein denaturation (myofibrillar shrinkage) during heating can be accelerated by the destabilisation of the structure of myosin and actin after ageing. Therefore, the weakened protein structure in aged meat is unable to retain or trap as much water during cooking (Hughes et al., 2014). Accordingly, changes in the WBSF and cook loss in beef at the 7th and 14th days post-mortem would not be expected to be reflected in the Raman spectral information of the 3rd day, hence reducing the potential of spectra on the 7th and 14th days to predict WBSF and cook loss measured on the 3rd day.

\subsubsection{Prediction of IMF, moisture and protein}

A performance summary of PLSR models for predicting IMF, moisture and protein in each independent sample group is shown in Table $4 . \mathrm{R}^{2} \mathrm{C}$ values (0.74-0.92) of the calibration were generally higher than their $\mathrm{R}^{2} \mathrm{CV}$ values $(0.63-0.85)$ of the leave-one-out cross-validation for IMF prediction. $\mathrm{R}^{2} \mathrm{C}$ values of $0.73-0.97$ with RMSEC of $0.22-0.65 \% \mathrm{w} / \mathrm{w}$ and $\mathrm{R}^{2} \mathrm{CV}$ values of $0.61-0.91$ with RMSECV of $0.39-0.82 \% \mathrm{w} / \mathrm{w}$ were obtained for moisture prediction. While for the protein content prediction, the obtained $R^{2} C$ and $R^{2} C V$ values are in the ranges of $0.75-0.82$ and $0.61-0.70$ with RMSEC and RMSECV values in the ranges of $0.28-0.32 \% \mathrm{w} / \mathrm{w}$ and $0.37-0.43 \% \mathrm{w} / \mathrm{w}$ respectively. The best performing models were developed using the Raman spectra pretreated by Savitzky Golay 2nd derivative using 2nd polynomial with 9 smoothing points. Most informative spectral variables were enhanced using the 2nd derivative. Therefore, a reduced number of spectral variables were retained for developing PLSR prediction models after the Martens' uncertainty tests (Table 4). Models developed using Raman spectra collected on the 3rd day post-mortem had a better prediction for IMF and moisture than those collected on the 7th and 14th days, while there was no significant difference for protein prediction. Calibration and cross-validation results of the best performing PLSR models are 
Table 5

Summary of PLSR model performances (Raman shift $1300-2800 \mathrm{~cm}^{-1}$ ) for TC, HYP and CSol prediction in bull beef.

\begin{tabular}{|c|c|c|c|c|c|c|c|c|}
\hline & Sample & Raman data pre-treatment with the Martens' uncertainty test & $\begin{array}{l}\text { Numbers of spectral variables } \\
\text { retained }\end{array}$ & \# PLS loadings & $\mathrm{R}^{2} \mathrm{C}$ & RMSEC & $\mathrm{R}^{2} \mathrm{CV}$ & RMSECV \\
\hline \multirow[t]{6}{*}{ TC } & Day 3 & $\begin{array}{l}\text { S.G. } 1 \text { st der. using } 5 \text { th polynomial with } 7 \text { smooth points } \\
+ \text { nor.u.v. }\end{array}$ & 131 & 3 & 0.97 & 0.19 & 0.79 & 0.56 \\
\hline & $(\mathrm{n}=36)$ & S.G. 2nd der. using 2th polynomial with 9 smooth points & 21 & 1 & 0.82 & 0.49 & 0.78 & 0.56 \\
\hline & Day 7 & S.G. 1st der. using 5 th polynomial with 7 smooth points + nor.u.v. & 121 & 1 & 0.74 & 0.59 & 0.67 & 0.69 \\
\hline & $(\mathrm{n}=36)$ & S.G. 2nd der. using 2th polynomial with 9 smooth points & 106 & 2 & 0.80 & 0.51 & 0.59 & 0.77 \\
\hline & Day 14 & S.G. 1 st der. using 5 th polynomial with 7 smooth points + nor.u.v. & 53 & 1 & 0.66 & 0.67 & 0.58 & 0.76 \\
\hline & $(\mathrm{n}=36)$ & S.G. 2nd der. using 2 th polynomial with 9 smooth points & 49 & 1 & 0.62 & 0.72 & 0.52 & 0.82 \\
\hline \multirow[t]{6}{*}{ HYP } & Day 3 & $\begin{array}{l}\text { S.G. } 1 \text { st der. using } 5 \text { th polynomial with } 7 \text { smooth points } \\
+ \text { nor.u.v. }\end{array}$ & 112 & 3 & 0.97 & 0.03 & 0.79 & 0.07 \\
\hline & $(\mathrm{n}=36)$ & S.G. 2nd der. using 2th polynomial with 9 smooth points & 21 & 1 & 0.82 & 0.07 & 0.78 & 0.08 \\
\hline & Day 7 & S.G. 1st der. using 5 th polynomial with 7 smooth points + nor.u.v. & 121 & 1 & 0.74 & 0.08 & 0.67 & 0.09 \\
\hline & $(n=36)$ & S.G. 2nd der. using 2 th polynomial with 9 smooth points & 106 & 2 & 0.80 & 0.07 & 0.59 & 0.10 \\
\hline & Day 14 & S.G. 1st der. using 5 th polynomial with 7 smooth points + nor.u.v. & 81 & 2 & 0.80 & 0.07 & 0.62 & 0.10 \\
\hline & $(\mathrm{n}=36)$ & S.G. 2nd der. using 2th polynomial with 9 smooth points & 59 & 2 & 0.70 & 0.09 & 0.54 & 0.11 \\
\hline \multirow[t]{6}{*}{ CSol } & Day 3 & S.G. 1st der. using 5 th polynomial with 7 smooth points + nor.u.v. & 68 & 2 & 0.88 & 1.96 & 0.66 & 3.38 \\
\hline & $(\mathrm{n}=36)$ & S.G. 2nd der. using 2th polynomial with 9 smooth points & 58 & 1 & 0.73 & 2.94 & 0.65 & 3.45 \\
\hline & Day 7 & S.G. 1st der. using 5 th polynomial with 7 smooth points + nor.u.v. & 61 & 2 & 0.87 & 2.20 & 0.72 & 3.34 \\
\hline & $(\mathrm{n}=36)$ & S.G. 2nd der. using 2 th polynomial with 9 smooth points & 58 & 1 & 0.80 & 2.75 & 0.73 & 3.29 \\
\hline & Day 14 & S.G. 1st der. using 5th polynomial with 7 smooth points + nor.u.v. & 74 & 1 & 0.92 & 1.72 & 0.79 & 2.84 \\
\hline & $(n=36)$ & S.G. 2nd der. using 2 th polynomial with 9 smooth points & 102 & 2 & 0.95 & 1.30 & 0.88 & 2.15 \\
\hline
\end{tabular}

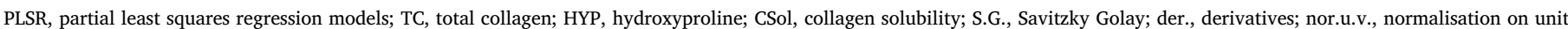

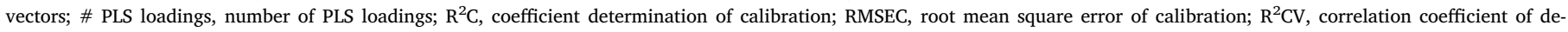

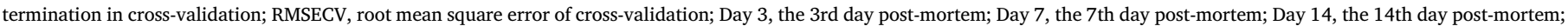
$\mathrm{n}$, numbers of samples.

shown in Fig. 2 c, d\& e. This phenomenon reflects the qualitative or quantitative changes of moisture and IMF during ageing.

Changes of IMF during ageing are mainly due to lipid oxidation, which is responsible for quality deterioration of meat during storage. Lipid peroxidation occurs mostly in phospholipid fraction, and particularly high degree of polyunsaturated fatty acids are more prone to be oxidation, which leads to off-flavour formation (rancidity), colour changes, drip loss, etc. (Wood et al., 2003). Although low temperature and vacuum packaging can prevent the rapid development of lipid oxidation, the process may continue due to a small amount of residual air in the package or the oxygen transmission through the packaging film. There is no change in IMF content during ageing while any chemical structure change may influence the prediction accuracy.

Moisture loss increases with ageing (Colle et al., 2015). Proteolysis of cytoskeletal proteins during ageing will affect water distribution. The larger water channels are mainly due to the extra-myofibrillar water in meat, which is related to integrin degradation as integrin attaches the cytoskeleton to the extracellular matrix. Moreover, the water channels could also be due to water resulting from the degradation of waterbinding proteins during the process of ageing (Pearce et al., 2011).

Changes of protein structure occur during the ageing process. A series of endogenous enzymatic systems have been demonstrated to contribute to softening of the myofibrillar structure and improved tenderness; the degraded proteins mainly include myosin, actin and cytoskeletal proteins (Longergan et al., 2010). Although the total amount of amino acid within muscle doesn't change during proteolysis, the location of individual amino acid may change or be split off to form free amino acids (Beattie et al., 2008). However, the results in the current study showed no significant difference in prediction performance of protein between the 3rd and 14th days probably due to the limitation of sample size.

\subsubsection{Prediction of total collagen, hydroxyproline and collagen solubility}

Results of PLSR models for the prediction of TC, HYP and CSol are summarised in Table 5. Models developed using the Raman spectra of the 3rd day post-mortem show a more satisfactory performance for the prediction of TC and HYP while for CSol, the best prediction performance was obtained on the 14th day. In particular, the models developed using S.G. 1st derivative and unit vector normalisation pre-treated
Raman data achieved an $\mathrm{R}^{2} \mathrm{C}$ of 0.97 and $\mathrm{R}^{2} \mathrm{CV}$ of 0.79 with RMSEC of $0.19 \% \mathrm{w} / \mathrm{w}$ and RMSECV of $0.56 \% \mathrm{w} / \mathrm{w}$ for the prediction of TC (Fig. 2f); with RMSEC of $0.03 \% \mathrm{w} / \mathrm{w}$ and RMSECV of $0.07 \% \mathrm{w} / \mathrm{w}$ for the prediction of HYP (Fig. $2 \mathrm{~g}$ ); and an $\mathrm{R}^{2} \mathrm{C}$ of $0.95, \mathrm{R}^{2} \mathrm{CV}$ of 0.88 , RMSEC of $1.30 \% \mathrm{w} / \mathrm{w}$, RMSECV of $2.15 \% \mathrm{w} / \mathrm{w}$ for the prediction of CSol (Fig. 2h). The slightly lower prediction ability of PLSR models for TC and HYP based on Raman spectra of the 7th and 14th days post-mortem compared to the 3rd day can be explained by the ultrastructural and quantitative changes of collagen during ageing.

From the ultrastructure point of view, proteoglycan is degraded, thus the linkage between collagen fibrils is weakened. The disintegrated total collagen networks appear to decrease the mechanical strength of IMCT and lead to an improvement of tenderness in uncooked meat (Nishimura, 2015). Furthermore, the perimysium and epimysium also undergo damage as a result of proteolytic attack. Within the collagen fibrils of muscle, collagenases or $\mathrm{Zn}^{2+}$ metalloproteinases are able to break down matrix components and cleave the triple collagen helix (Woessner, 1991). After helix cutting, the single $\alpha$-helix can be hydrolysed by cathepsins, thus peptides and free-amino-acids can be released in lysosomes (Feidt et al., 1996). For the quantity aspect, total free hydroxyproline in LD of bovine increased from $3 \% \mathrm{w} / \mathrm{w}$ at the $3 \mathrm{rd}$ day post-mortem to $11 \% \mathrm{w} / \mathrm{w}$ at the 14 th day (Feidt et al., 1996).

Dutson \& Lawrie (1974) reported that soluble collagen increased from $1 \mathrm{~h}$ to 14 days post-mortem expressed as more hydroxyproline after hydrolysis due to the size of collagen fragments decreasing during storage. Similarly, a weak but significantly increased solubility of collagen fractions was observed in bovine muscles after ageing for 14 days (Stanton \& Light, 1987). In the current study, the solubility (CSol) prediction showed an increased trend during ageing.

\subsubsection{Regression coefficients of the prediction equations}

The relevant regression coefficient plots of the best performing models are shown in Fig. 3. Regression coefficient plots show multiple maxima and minima of intensities, which consistently happened in the $1300-2800 \mathrm{~cm}^{-1}$ range for the prediction of WBSF, cook loss, moisture and IMF (Fig. 3 a, b, c, e). Fig. $3 \mathrm{f} \& \mathrm{~g}$ show regression coefficient intensities at similar Raman frequencies for the prediction of total collagen and hydroxyproline, which shows the strong correlation between them. Theoretically, collagen is the only molecule in muscle which 

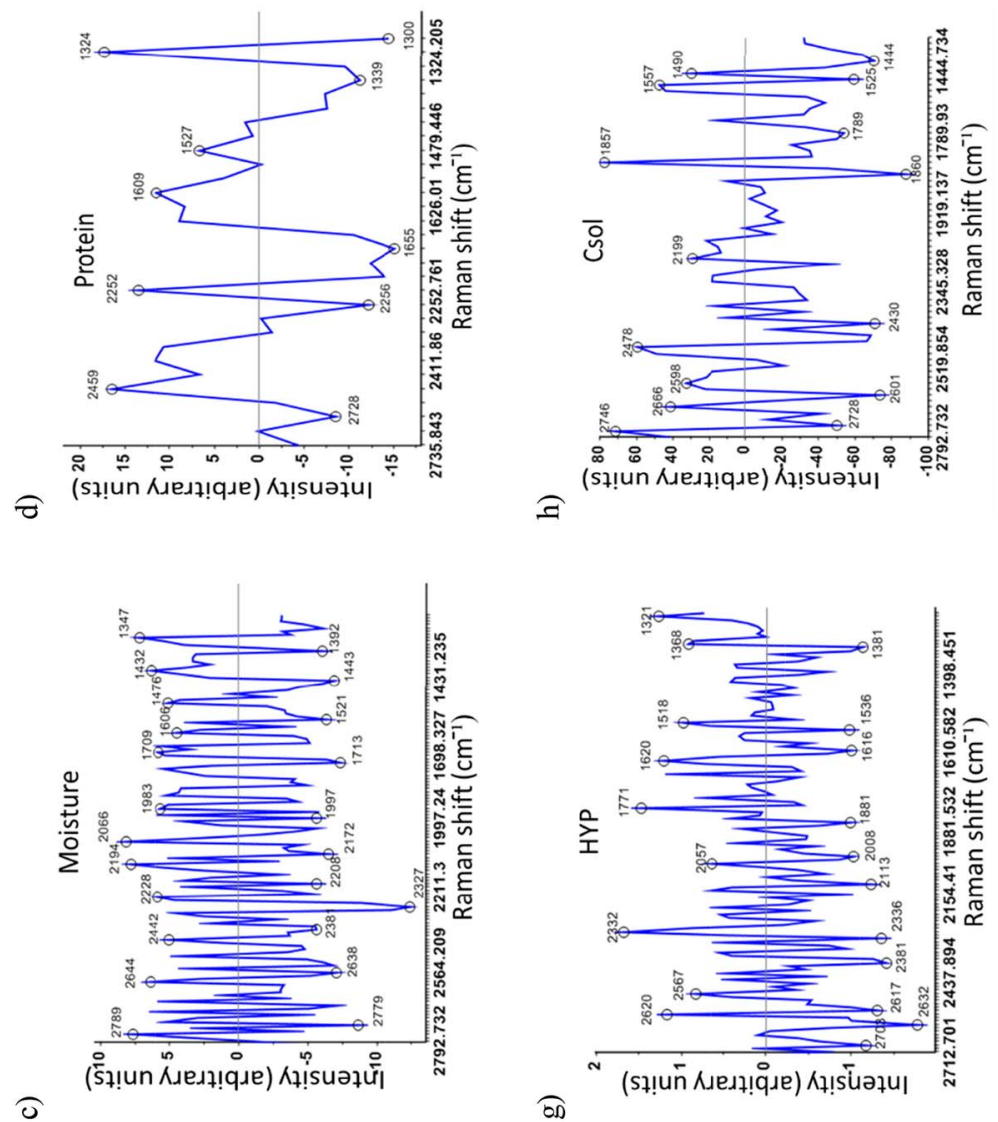

o
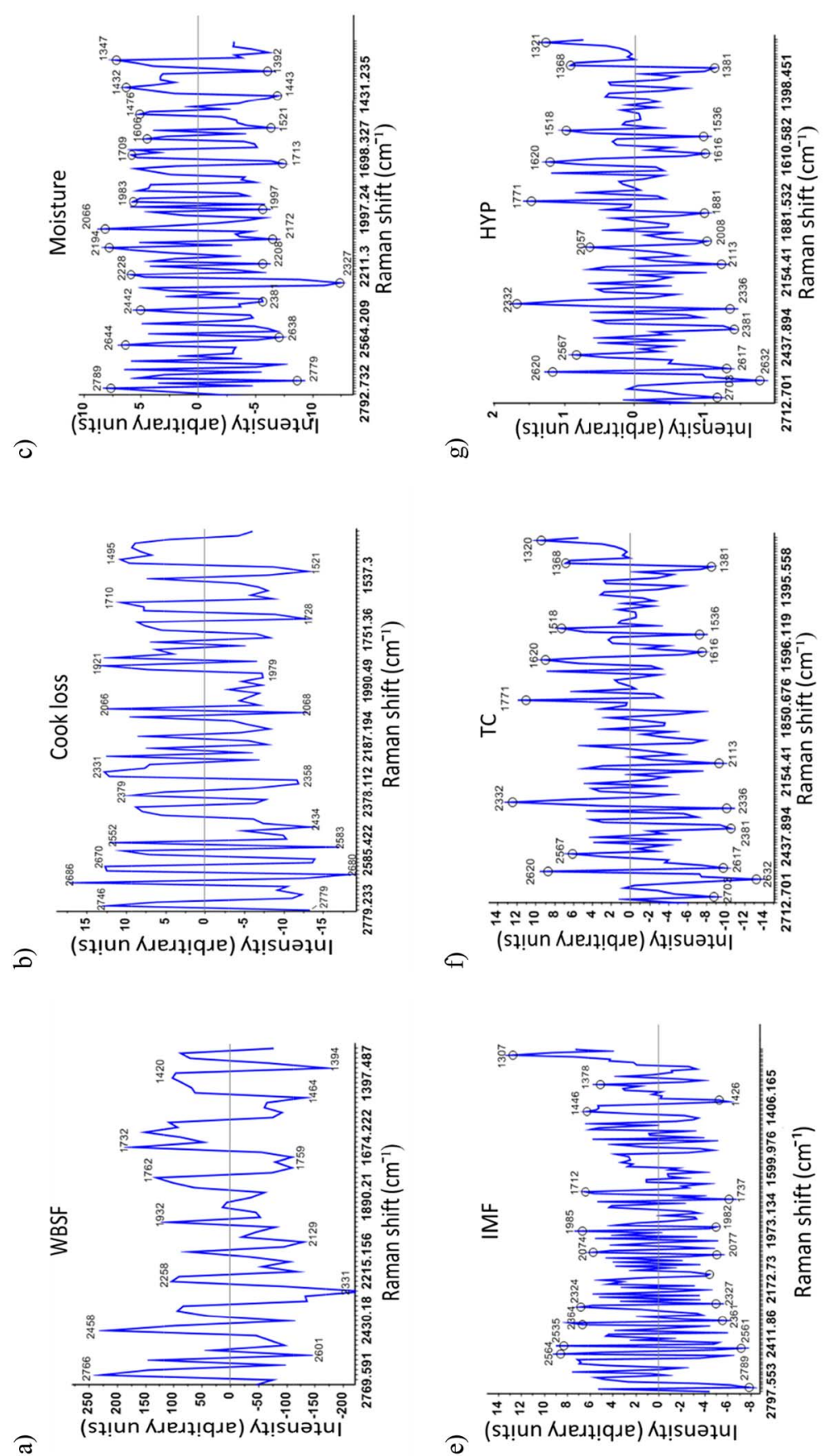

$\Theta$

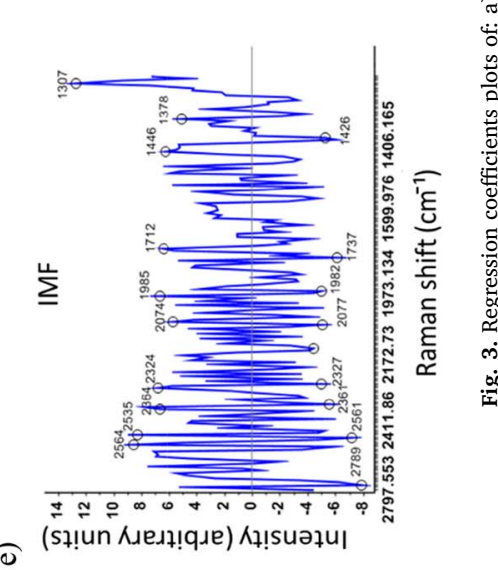


Table 6

Summary of PLS-DA performances (Raman shift $1300-2800 \mathrm{~cm}^{-1}$ ) for the detection of samples from 15- and 19-month old bulls.

\begin{tabular}{|c|c|c|c|c|c|c|c|c|}
\hline \multirow[b]{2}{*}{ Sample } & \multirow[b]{2}{*}{ Data type } & \multirow[b]{2}{*}{$\begin{array}{l}\text { Numbers of spectral } \\
\text { variables retained }\end{array}$} & \multicolumn{5}{|c|}{ Classification results of cross-validation } & \multirow[b]{2}{*}{$\begin{array}{l}\% \text { correct } \\
\text { classification (CC) }\end{array}$} \\
\hline & & & $\begin{array}{l}\text { No. of PLS } \\
\text { loadings }\end{array}$ & $\begin{array}{l}\text { TP (true } \\
\text { positive) }\end{array}$ & $\begin{array}{l}\text { TN (true } \\
\text { negative) }\end{array}$ & $\begin{array}{l}\text { FP (false } \\
\text { positive) }\end{array}$ & $\begin{array}{l}\text { FN (false } \\
\text { negative) }\end{array}$ & \\
\hline \multirow[t]{2}{*}{ Day $7(n=55)$} & S.G. 1st der. using 5th & 1557 & 2 & 26 & 29 & 0 & 0 & 100 \\
\hline & $\begin{array}{l}\text { polynomial with } 7 \text { smooth } \\
\text { points }+ \text { nor.u.v. }\end{array}$ & 282 & 1 & 26 & 29 & 0 & 0 & 100 \\
\hline \multirow{2}{*}{$\begin{array}{l}\text { Day } 14 \\
\qquad(n=55)\end{array}$} & S.G. 1st der. using 5th & 1557 & 1 & 19 & 22 & 7 & 7 & 74.5 \\
\hline & $\begin{array}{l}\text { polynomial with } 7 \text { smooth } \\
\text { points }+ \text { nor.u.v. }\end{array}$ & 161 & 1 & 25 & 27 & 1 & 2 & 94.5 \\
\hline
\end{tabular}

$\mathrm{n}$, numbers of samples.

a)

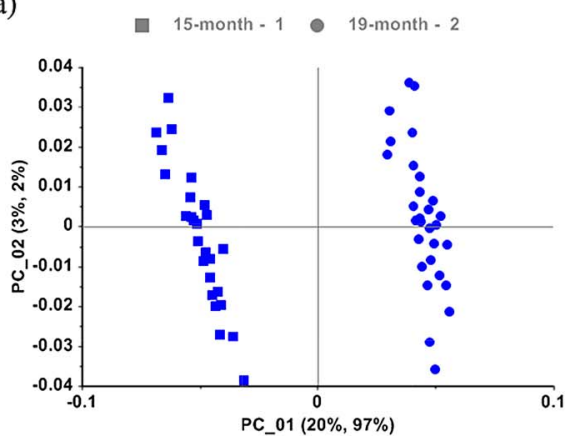

d)

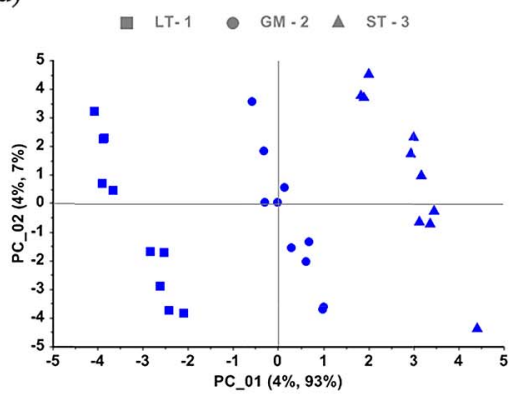

b)

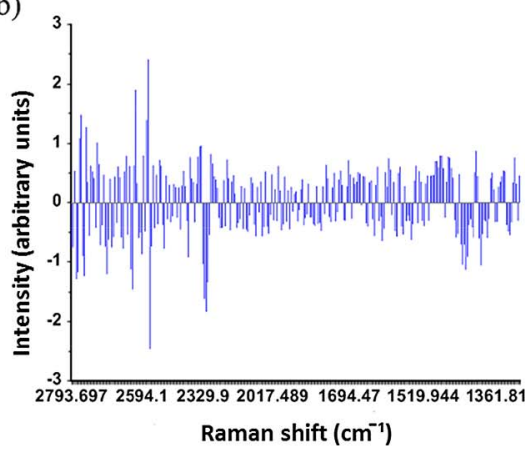

e)

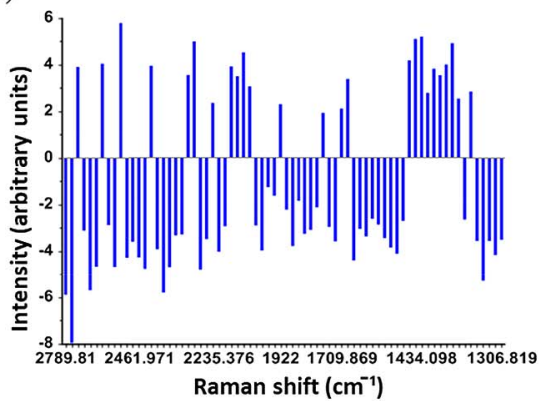

c)

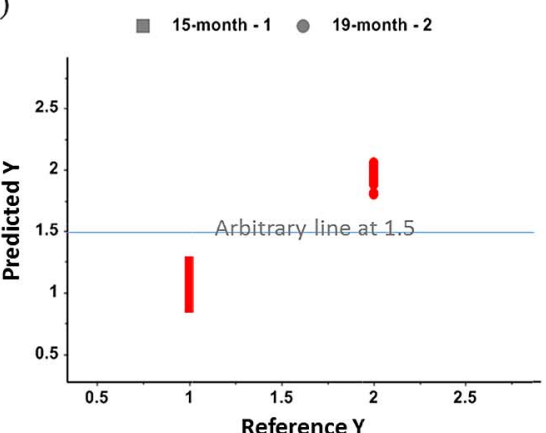

f)

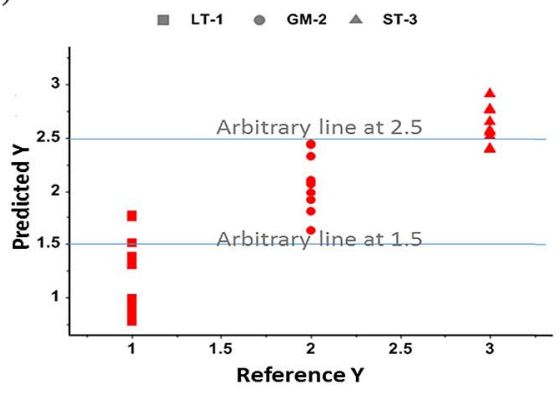

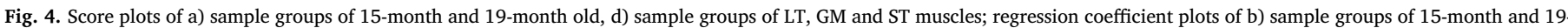

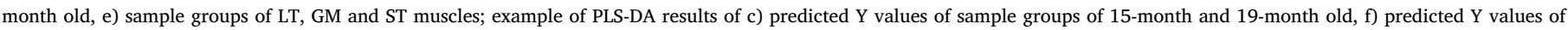
sample groups of LT, GM and ST muscles.

contains hydroxyproline, a type of pro-collagen which accounts for $14 \%$ of collagen. (Bailey \& Light, 1989). For the prediction of protein content, intensity changes specifically occurred around $1300-1339 \mathrm{~cm}^{-1}$ which is likely related to cis form secondary amides (amide III group); $1609-1655 \mathrm{~cm}^{-1}$ correlates with arginine, phenylalanine, tryptophan in the region of amide I group (Beattie et al., 2004); 2252-2256, $2459-2728 \mathrm{~cm}^{-1}$ may relate to the carbonyl group of proteins (Smith \& Dent, 2005). For collagen solubility prediction, regression coefficient intensity shifts happened at $1444-1490 \mathrm{~cm}^{-1}$ which have been assigned to $\mathrm{C}=\mathrm{O}$ stretching, $\mathrm{C}=\mathrm{C}$ stretching, $\mathrm{CH}_{2}$ scissoring and $\mathrm{C}-\mathrm{H}$ bonds of aliphatic chains of lipids (Smith \& Dent, 2005); $1525-1557 \mathrm{~cm}^{-1}$ have been assigned to $\mathrm{C}=\mathrm{N}$ stretching bonds or tryptophan (amide II); $1857-1860 \mathrm{~cm}^{-1}$ have been assigned to $\mathrm{C}-\mathrm{H}$ and $\mathrm{S}-\mathrm{H}$ stretching bonds and $2430-2746 \mathrm{~cm}^{-1}$ may be assigned to $\mathrm{P}-\mathrm{H}$ stretching bonds of phosphines or $\mathrm{S}-\mathrm{H}$ stretching bonds of mercaptans, aliphatic thiols and thiophenols (Socrates, 2001). Other possibly related function groups of chemical compounds and Raman shifts are listed in Supplementary materials. However, compared with the fingerprint range (900-1800 $\mathrm{cm}^{-1}$ ) of Raman shifts, the related chemical bonds in the range of $1300-2800 \mathrm{~cm}^{-1}$ are not widely reported for meat studies.

\subsection{Discrimination between production systems}

\subsubsection{Slaughter age discrimination}

For the discrimination of beef from 15- or 19-month old bulls, $100 \%$ correct sample identification was achieved by PLS-DA models developed using Raman spectral data collected at the 7th day post-mortem and pre-treated by S.G. 1st derivative using 5th polynomial with 7 smoothing points with normalisation on unit vector. After spectral variable selection, 282 of the spectral variables $(n=1557)$ were retained for the model development. A $94.5 \%$ correct sample identification was achieved by PLS-DA models developed using Raman spectral data collected at the 14th day post-mortem using 161 retained spectral variables (Table 6). It has been reported that 19-month old bulls produced tougher beef than that from 15-month old bulls (Renand et al., 2001). Collagen characteristics were greatly influenced by slaughter age, with older animals having a higher proportion of heat-stable crosslinks, which contributed to the lower collagen solubility (Bailey, 1985). The best performing PLS-DA model for the determination of beef 
Table 7

Summary of PLS-DA performances (Raman shift $1300-2800 \mathrm{~cm}^{-1}$ ) for the detection of bull beef samples of LT, ST and GM muscles.

\begin{tabular}{|c|c|c|c|c|c|c|c|c|c|}
\hline \multirow[b]{2}{*}{ Sample } & \multirow[b]{2}{*}{ Data type } & \multirow[b]{2}{*}{$\begin{array}{l}\text { Numbers of spectral } \\
\text { variables retained } \\
(1300-2800 \mathrm{~cm})\end{array}$} & \multirow[b]{2}{*}{$\begin{array}{l}\text { No. of PLS } \\
\text { loadings }\end{array}$} & \multirow[b]{2}{*}{$\begin{array}{l}\text { Predicted } \\
\text { muscle types }\end{array}$} & \multicolumn{5}{|c|}{ Classification results of cross-validation } \\
\hline & & & & & $\begin{array}{l}\text { TP (True } \\
\text { positive) }\end{array}$ & $\begin{array}{l}\text { TN (True } \\
\text { negative) }\end{array}$ & $\begin{array}{l}\text { FP (False } \\
\text { positive) }\end{array}$ & $\begin{array}{l}\text { FN (False } \\
\text { negative) }\end{array}$ & $\begin{array}{l}\% \text { correct } \\
\text { classification (CC) }\end{array}$ \\
\hline \multirow{6}{*}{$\begin{array}{l}\text { Day } 7 \\
\qquad(\mathrm{n}=30)\end{array}$} & \multirow{3}{*}{$\begin{array}{l}\text { S.G. 1st der. using 5th } \\
\text { polynomial with } 7 \\
\text { smooth points } \\
+ \text { nor.u.v. }\end{array}$} & \multirow[t]{3}{*}{70} & \multirow[t]{3}{*}{1} & 1-LT & 7 & 18 & 3 & 2 & \multirow[t]{3}{*}{83.3} \\
\hline & & & & 2-ST & 10 & 15 & 0 & 5 & \\
\hline & & & & 3-GM & 8 & 17 & 2 & 5 & \\
\hline & \multirow{3}{*}{$\begin{array}{l}\text { S.G. 2nd der. using } 2 \text { th } \\
\text { polynomial with } 9 \\
\text { smooth points }\end{array}$} & \multirow[t]{3}{*}{72} & \multirow[t]{3}{*}{1} & 1-LT & 8 & 18 & 2 & 2 & \multirow[t]{3}{*}{86.7} \\
\hline & & & & 2-ST & 9 & 17 & 1 & 3 & \\
\hline & & & & 3-GM & 9 & 17 & 1 & 3 & \\
\hline \multirow{6}{*}{$\begin{array}{l}\text { Day } 14 \\
\qquad(\mathrm{n}=30)\end{array}$} & \multirow{3}{*}{$\begin{array}{l}\text { S.G. 1st der. using } 5 \text { th } \\
\text { polynomial with } 7 \\
\text { smooth points } \\
+ \text { nor.u.v. }\end{array}$} & \multirow[t]{3}{*}{55} & \multirow[t]{3}{*}{1} & $1-\mathrm{LT}$ & 7 & 14 & 3 & 6 & \multirow[t]{3}{*}{70.0} \\
\hline & & & & 2-ST & 9 & 12 & 1 & 7 & \\
\hline & & & & 3-GM & 5 & 16 & 5 & 4 & \\
\hline & \multirow{3}{*}{$\begin{array}{l}\text { S.G. } 2 \text { nd der. using } 2 \text { th } \\
\text { polynomial with } 9 \\
\text { smooth points }\end{array}$} & \multirow[t]{3}{*}{53} & \multirow[t]{3}{*}{2} & 1-LT & 9 & 16 & 1 & 4 & \multirow[t]{3}{*}{83.3} \\
\hline & & & & 2-ST & 8 & 17 & 2 & 3 & \\
\hline & & & & 3-GM & 8 & 17 & 2 & 3 & \\
\hline
\end{tabular}

n, numbers of samples.

samples from two age groups is shown in Fig. 4c; these two sample groups can be completely defined by the arbitrary cut-off line at 1.5 on the y-axis. The score plot of samples (Fig. 4a) shows that components (PC1 \& 2) explain $23 \%$ of the $x$-variance and $99 \%$ of the $y$-variance. Fig. 4b shows the relevant regression coefficients of spectral variables in the $1300-2800 \mathrm{~cm}^{-1}$ range for the best performing PLS-DA models developed.

\subsubsection{Muscle discrimination}

Beef samples from three different muscles (LT, ST and GM) were discriminated with 70.0-86.7\% correct classification using PLS-DA models (Table 7). Results showed PLS-DA models developed using 53 to 72 similar spectral variables after data pre-treatments by S.G. 1st derivative using 5th polynomial with 7 smooth points (with normalisation on unit vectors) or S.G. 2nd derivative using 2nd polynomial with 9 smooth points. The best performing model was developed using 72 retained spectral variables collected at the 7th day post-mortem with $86.7 \%$ correct classification. In Fig. 4f, 4 samples were misclassified, including two samples of the LT group which are above the arbitrary cut-off line at 1.5 on the y-axis, one of the ST group was above the line at 2.5 on the $y$-axis and one of the GM group was under the line at 2.5. The relevant regression coefficient plot is shown in Fig. 4e. The score plot show that samples of these three muscle groups can be explained using components (PC1 \& 2) with $8 \%$ of $x$-variance and $100 \%$ of $y$ variance explained (Fig. 4d). In this score plot, the cluster of GM was located in the middle between the other two muscle clusters; this corresponds to the difference in eating quality of three muscle types. It has been noted that ST had higher WBSF than LT while WBSF of GM took an intermediate position between ST and LT (Belew et al., 2003). In contrast, the IMF content was higher in LT than ST, and GM also took an intermediate position. ST and GM had higher total collagen content than LT, and collagen solubility was greater in LT and GM than ST (Jeremiah et al., 2003b).

Generally, PLS-DA modelling based on Raman spectra of the 7th day post-mortem showed similar discrimination results to those based on the spectra of the 14th day.

\section{Conclusions}

This study demonstrated the potential of Raman spectroscopy to assess eating quality related physico-chemical characteristics in young dairy bull beef aged for different times. PLSR models based on the $1300-2800 \mathrm{~cm}^{-1}$ wavelength range yielded the best results for both prediction and discrimination purposes. The prediction ability of PLSR models developed using spectra of the 7th or 14th day post-mortem was lower (except for collagen solubility and protein prediction) than those at the 3rd day, reflecting the ultrastructural changes in beef with ageing. Improved prediction performance can be achieved using multiple muscle types. PLS-DA modelling showed that Raman spectroscopy has potential to discriminate beef characteristics such as age and muscle type and results were not greatly influenced by post-mortem ageing. Future work should investigate the application of Raman spectroscopy for on-line assessment of meat eating quality related physico-chemical traits. Furthermore, the Raman frequency range of $1300-2800 \mathrm{~cm}^{-1}$ still merits further investigation for meat sensory analysis.

\section{Funding sources}

This research was funded by the Teagasc Walsh Fellowship Scheme, Ireland.

\section{Conflict of interest}

The authors declare no conflict of interest in the preparation of this manuscript.

\section{Notes}

This project was submitted to the Teagasc Animal Ethics Committee who advised that provided best husbandry practice was followed no ethical issues would arise.

\section{Acknowledgements}

We wish to acknowledge Teagasc Johnstown Castle Research Centre for rearing the dairy bulls and Dawn Meat for slaughtering the dairy bulls.

\section{Appendix A. Supplementary data}

Supplementary data to this article can be found online at http://dx. doi.org/10.1016/j.foodres.2017.06.056.

\section{References}

Alomar, D., Gallo, C., Castañeda, M., \& Fuchslocher, R. (2003). Chemical and discriminant analysis of bovine meat by near infrared reflectance spectroscopy (NIRS) Meat Science, 63, 441-450.

AOAC 985.14 (1991). Moisture in meat and poultry products-rapid microwave drying 
method. In P. Cuniff (Ed.), Official Methods of Analysis of AOAC International(15th ed.). (USA: Arlington, VA).

AOAC 992.15 (1992). Crude protein in meat and meat products including pet foodscombustion method. In P. Cuniff (Ed.), Official Methods of Analysis of AOAC International(15th ed.). (USA: Arlington, VA).

Archile-Contreras, A. C., Mandell, I. B., \& Purslow, P. P. (2010). Disparity of dietary effects on collagen characteristics and toughness between two beef muscles. Meat Science, 86, 491-497.

Bailey, A. J. (1985). The roll of collagen in the development of muscle and its relationship to eating quality. Journal of Animal Science, 60, 1580-1587.

Bailey, A. J., \& Light, N. D. (1989). Connective Tissue in Meat and Meat Products. London: Elsevier Applied Science.

Bauer, A., Scheier, R., Eberle, T., \& Schmidt, H. (2016). Assessment of tenderness of aged bovine gluteus medius muscles using Raman spectroscopy. Meat Science, 115, 27-33.

Beattie, J. R., Bell, S. E. J., Borggaard, C., \& Moss, B. W. (2008). Preliminary investigations on the effects of ageing and cooking on the Raman spectra of porcine longissimus dorsi. Meat Science, 80, 1205-1211.

Beattie, J. R., Bell, S. E. J., Farmer, L. J., Moss, B. W., \& Patterson, D. (2004). Preliminary investigation of the application of Raman spectroscopy to the prediction of the sensory quality of beef silverside. Meat Science, 66, 903-913.

Belew, J. B., Brooks, J. C., McKenna, D. R., \& Savell, J. W. (2003). Warner-Bratzler shear evaluations of 40 bovine muscles. Meat Science, 64, 507-512.

Chambaz, A., Scheeder, M. R. L., Kreuzer, M., \& Dufey, P. A. (2003). Meat quality of Angus, Simmental, Charolais and Limousin steers compared at the same intramuscular fat content. Meat Science, 63, 491-500.

Chong, I.-G., \& Jun, C.-H. (2005). Performance of some variable selection methods when multicollinearity is present. Chemometrics and Intelligent Laboratory Systems, 78(1-2), 103-112.

Christensen, M., Ertbjerg, P., Failla, S., Sañudo, C., Richardson, R. I., Nute, G. R., et al. (2011). Relationship between collagen characteristics, lipid content and raw and cooked texture of meat from young bulls of fifteen European breeds. Meat Science, 87, 61-65.

Colgrave, M. L., Allingham, P. G., \& Jones, A. (2008). Hydroxyproline quantification for the estimation of collagen in tissue using multiple reaction monitoring mass spectrometry. Journal of Chromatography A, 1212, 150-153.

Colle, M. J., Richard, R. P., Killinger, K. M., Bohlscheid, J. C., Gray, A. R., Loucks, W. I., ... Doumit, M. E. (2015). Influence of extended aging on beef quality characteristics and sensory perception of steaks from the gluteus medius and longissimus lumborum. Meat Science, 110, 32-39.

Cozzolino, D., De Mattos, D., \& Martins, V. (2002). Visible/near infrared reflectance spectroscopy for predicting composition and tracing system of production of beef muscles. Animal Science, 74, 477-484.

Damez, J.-L., \& Clerjon, S. (2008). Meat quality assessment using biophysical methods related to meat structure. Meat Science, 80, 132-149.

De Marchi, M., Berzaghi, P., Boukha, A., Mirisola, M., \& Gallo, L. (2007). Use of near infrared spectroscopy for assessment of beef quality traits. Italian Journal of Animal Science, 6, 421-423.

Dransfield, E. (1977). Intramuscular composition and texture of beef muscle. Journal of the Science of Food and Agriculture, 28, 833-842.

Dutson, T. R., \& Lawrie, R. A. (1974). Release of lysosomal enzymes during post mortem conditioning and their relationship to tenderness. Journal of Food Science and Technology, 9, 43-50.

Feidt, C., Petit, A., Bruas-Reignier, F., \& Brun-Bellut, J. (1996). Release of free aminoacids during ageing in bovine meat. Meat Science, 44, 19-25.

Fowler, S. M., Ponnampalam, E. N., Schmidt, H., Wynn, P., \& Hopkins, D. L. (2015). Prediction of intramuscular fat content and major fatty acid groups of lamb $M$. longissimus lumborum using Raman spectroscopy. Meat Science, 110, 70-75.

Fowler, S. M., Schmidt, H., van de Ven, R., Wynn, P., \& Hopkins, D. L. (2014). Raman spectroscopy compared against traditional predictors of shear force in lamb $M$. longissimus lumborum. Meat Science, 98, 652-656.

Frylinck, L., Strydom, P. E., Webb, E. C., \& du Toit, E. (2013). Effect of South African beef production systems on post-mortem muscle energy status and meat quality. Meat Science, 93, 827-837.

Herrero, A. M. (2008). Raman spectroscopy a promising technique for quality assessment of meat and fish: A review. Food Chemistry, 107, 1642-1651.

Herrero, A. M., Carmona, P., Cofrades, S., \& Jimenez-Colmenero, F. (2008). Raman spectroscopic determination of structural changes in meat batters upon soy protein addition and heat treatment. Food Research International, 41, 765-772.

Hill, F. (1966). The solubility of intramuscular collagen in meat animals of various ages. Journal of Food Science, 31, 161-166.

Hughes, J. M., Oiseth, S. K., Purslow, P. P., \& Warner, R. D. (2014). A structural approach to understanding the interactions between colour, water-holding capacity and tenderness. Meat Science, 98, 520-532.

Jeremiah, L. E., Dugan, M. E. R., Aalhus, J. L., \& Gibson, L. L. (2003a). Assessment of the relationship between chemical components and palatability of major beef muscles and muscle groups. Meat Science, 65, 1013-1019.

Jeremiah, L. E., Dugan, M. E. R., Aalhus, J. L., \& Gibson, L. L. (2003b). Assessment of the chemical and cooking properties of the major beef muscles and muscle groups. Meat Science, 65, 985-992.

Li-Chan, E. C. Y. (1996). The applications of Raman spectroscopy in food science. Trends in Food Science and Technology, 7, 361-370.

Lonergan, E. H., Zhang, W., \& Lonergan, S. M. (2010). Biochemistry of postmortem muscle-Lessons on mechanisms of meat tenderization. Meat Science, 86, 184-195.

Martens, H., \& Martens, M. (2000). Modified jack-knife estimation of parameter uncertainty in bilinear modelling by partial least squares regression (PLSR). Food Quality and Preference, 11, 5-16.

Miller, R. K. (2002). Factors affecting the quality of raw meat. In J. P. Kerry, J. F. Kerry, \& D. Ledward (Eds.), Meat processing - Improving quality (pp. 27-63). England: Woodhead Publishing Co, Cambridge.

Muchenje, V., Dzama, K., Chimonyo, M., Raats, J. G., \& Strydom, P. E. (2008). Meat quality of Nguni, Bonsmara and Aberdeen Angus steers raised on natural pasture in the Eastern Cape, South Africa. Meat Science, 79, 20-28.

Muchenje, V., Dzama, K., Chimonyo, M., Strydom, P. E., Hugo, A., \& Raats, J. G. (2009). Some biochemical aspects pertaining to beef eating quality and consumer health: A review. Food Chemistry, 112, 279-289.

Nishimura, T. (2015). Role of extracellular matrix in development of skeletal muscle and postmortem aging of meat. Meat Science, 109, 48-55.

Pearce, K. L., Rosenvold, K., Andersen, H. J., \& Hopkins, D. L. (2011). Water distribution and mobility in meat during the conversion of muscle to meat and ageing and the impacts on fresh meat quality attributes-A review. Meat Science, 89, 111-124.

Prieto, N., Roehe, R., Lavín, P., Batten, G., \& Andrés, S. (2009). Application of near infrared reflectance spectroscopy to predict meat and meat products quality: A review. Meat Science, 83, 175-186.

Renand, G., Picard, B., Touraille, C., Berge, P., \& Lepetit, J. (2001). Relationships between muscle characteristics and meat quality traits of young Charolais bulls. Meat Science, $59,49-60$.

Ripoll, G., Albertí, P., Panea, B., Olleta, J. L., \& Sañudo, C. (2008). Near-infrared reflectance spectroscopy for predicting chemical, instrumental and sensory quality of beef. Meat Science, 80, 697-702.

Rødbotten, R., Nilsen, B. N., \& Hildrum, K. I. (2000). Prediction beef quality attributes from early post mortem near infrared reflectance spectra. Food Chemistry, 69, 427-436.

Schmidt, H., Scheier, R., \& Hopkins, D. L. (2013). Preliminary investigation on the relationship of Raman spectra of sheep meat with shear force and cooking loss. Meat Science, 93, 138-143.

Scollan, N., Hocquette, J.-F., Nuernberg, K., Dannenberger, D., Richardson, I., \& Moloney, A. (2006). Innovations in beef production systems that enhance the nutritional and health value of beef lipids and their relationship with meat quality: A review. Meat Science, 74, 17-33.

Shackelford, S. D., Morgan, J. B., Cross, H. R., \& Savell, J. W. (1991). Identification of threshold levels for Warner Bratzler shear force in top loin steaks. Journal of Muscle Foods, 2, 289-296.

Silva, J. A., Patarata, L., \& Martins, C. (1999). Influence of ultimate $\mathrm{pH}$ on bovine meat tenderness during ageing. Meat Science, 52, 453-459.

Smith, E., \& Dent, G. (2005). Modern Raman spectroscopy - A practical approach (1st ed.). England: John Wiley and Sons Ltd, Chichester (Chapter 1).

Socrates, G. (2001). Infrared and Raman characteristic group frequencies: Tables and charts (3rd ed.). England: John Wiley and Sons Ltd, Chichester (Chapter 1).

Stanton, C., \& Light, N. (1987). The effects of conditioning on meat collagen: Part 1evidence for gross in situ proteolysis. Meat Science, 21, 249-265.

Tran, T. N., Afanador, N. L., Buydens, L. M. C., \& Blanchet, L. (2014). Interpretation of variable importance in Partial Least Squares with Significance Multivariate Correlation (sMC). Chemometrics and Intelligent Laboratory Systems, 138, 153-160.

Troy, D. J., \& Kerry, J. P. (2010). Consumer perception and the role of science in the meat industry. Meat Science, 86, 214-226.

Woessner, J. F. (1991). Matrix metalloproteinases and their inhibitors in connective tissue remodelling. FASEB Journal, 5, 2145-2154.

Wood, J. D., Richardson, R. I., Nute, G. R., Fisher, A. V., Campo, M. M., Kasapidou, E., ... Enser, M. (2003). Effects of fatty acids on meat quality: A review. Meat Science, 66, $21-32$.

Xiong, Z., Sun, D.-W., Xie, A., Han, Z., \& Wang, L. (2015). Potential of hyperspectral imaging for rapid prediction of hydroxyproline content in chicken meat. Food Chemistry, 175, 417-422. 